\title{
Community Participation Medico-Legal Concepts to Identify Unclaimed or Missing Dead Bodies from Public Mortuaries to Improve Public Health in Western Kenya
}

\author{
Maurice B. Silali*, Odero W, Rogena E
}

Department of Human Anatomy, Maseno University, Kenya

\begin{abstract}
Community participation in medico-legal form bench-mark of health determinants and quality integrated services towards criminal justice support in health. Globally, over 44 million cases of unclaimed bodies or missing dead persons (UCBOMDPs) occur annually, $88 \%$ of these cases are in Sub Saharan Africa. In western Kenya and Kenya the rate of UCBOMDPs from road traffic accidents accounts $30 \%$ and $10 \%$ respectively, $80 \%$ of these UCBOMDPs are associated with limited community participation/next of kins in identification of UCBOMDPs, thus prevailing chronic prevalence of occupational health and safety hazards in public mortuaries. The study aimed to assess extent of community participation, uptake of community mortuary services and awareness on quality medico-legal concepts, training, embalming and assess how of knowledge, attitude and practices (KAP) of service providers influence the uptake of medico-legal concepts to mitigate occupational health and safety hazards and improve health. In Exploratory and cross sectional, 235 respondents were investigated through purposive and saturated sampling using structured questionnaires, focus group discussions (FGDs), observations and key informant interviews (KII) guides to collect data. Analysed statistical inferences and contents analysis to saturation, results showed, $94 \%$ of mortuary service providers in tier 4 were primary and secondary education drop outs of males, on contract jobs with limited access to quality forensic in mortuary science, contrarily to trained females and males counterparts from tiers 5 and 6 mortuary facilities on permanent. Embalming by gravitation method significant OD $(1.2,0.44)$. Prevalence of male being admitted as UCBOMDPs in the community was significant with, $\mathrm{OD}(8.3,0.12), \mathrm{RR}(0.33), 95 \% \mathrm{Cl}(1.23,1.02)$, significance were associated with male deliberately leaving IDs in houses for anonymity. Community participation in medico-legal concepts were sufficient than Detective police with $\mathrm{OD}(0.43,6.0), 95 \% \mathrm{Cl}(2.12,1.34)$. Advocacy to empower community comprehensively and holistically in medico-legal concepts remains vital.
\end{abstract}

Keywords: Medico-legal; Community participation; Health by WHO 1998; Forensic pathology; Sustainable; Empowerments; Embalming

\section{Introduction}

Community participation in medico-legal concepts, enshrine forensic science which deals with roles of multidisciplinary teams (Mortuary service providers) and next of kins in synergistic community partnership with other integrated professionals to discover and achieve criminal justice support in health [1], to describe manner (natural, accident, suicide, homicide, or undetermined), and state the actual cause (disease, injury or abnormality) of death. [2] Chronic prevalence of decomposing death bodies is due to ineffective utilization of medicolegal laws [3], on UCBOMDPs [4]. Investigations of community involvement in medico-legal concepts are multifaceted and require expertise of multidisciplinary teams of skilled practitioners from various fields with appropriate, I-24/7 communication network, that enables investigators to access INTERPOL's range of criminal databases based on their demographic data and underlying causes such as persons missing by design, pick pocketing while still in crime of scene or with health problem [5]. Forensic capacity building, influence effective and efficient utilization of most health determinants that affect utilization of medico-legal concepts [6] by multidisciplinary teams (mortuary service providers) which include: Police of crimes, coroners, pathologists, forensic technologist, forensic odontologists, mortuary attendants and mourners [7]. However community participation in medico-legal concepts by mortuary service providers and community households from public mortuaries in western Kenya remains unclear.

Globally, World Population Data (WPD) sheet, indicates a global population clock of crude mortality due to UCBOMDPs in developing countries of 44 million every year, $88 \%$ of these cases are found in Sub Saharan Africa (SSA) [8]. Global Road Safety Partnership (GRSP) on the other hand demonstrates a mortality of UCBOMDPs of 1.2 million per year, majority being attributed to over speeding and reckless driving over which, $80 \%$ prevalence results to unclaimed death, injuries and disabled from road traffic accidents, which are against achievement of Road safety target on Sustainable Development by 2030 [9]. Those who succumb to death mostly become UCBOMDPs in public mortuaries, and community participation like next of kins or close relatives who are rarely found at time of incidence thus, lead to high prevalence of infectious diseases and other mortuary occupational and health hazards [10], hence need accessible and efficient community involvement to help trace their unclaimed deaths promptly. The cumulated decomposing death bodies in public mortuaries in Kenya are associated with limited capacities and inefficient participation of various communities in our society with diversity of cultures, as basic health determinants of health support to reduce disease incidence and other associated mortuary hazards [11]. Globally, INTERPOL country members use DNA Gateway to access UCBOMDPs and retain ownership of their profile data and control its submission by country members, and allow its destruction in accordance with their national laws [12], and these remains unstated in western Kenya.

In western Kenya, majority of UCBOMDPs are mainly attributed to road accidents with 3,000 unclaimed bodies in every 10,000 deaths [13], these bodies are admitted to public mortuaries, and overstay causing a budget strain on the health sector, Cumulated UCBOMDPs in most pubic mortuaries are due to persistent underutilization of medico-legal

*Corresponding author: Maurice B. Silali, Department of Human Anatomy, Maseno University, Kenya, Tel: +254720842994; E-mail: gmsilali@yahoo.com

Received April 04, 2017; Accepted April 26, 2017; Published April 30, 2017

Citation: Silali MB, Odero W, Rogena E (2017) Community Participation MedicoLegal Concepts to Identify Unclaimed or Missing Dead Bodies from Public Mortuaries to Improve Public Health in Western Kenya. J Health Med Informat 8: 260. doi: $10.4172 / 2157-7420.1000260$

Copyright: @ 2017 Silali MB. This is an open-access article distributed under the terms of the Creative Commons Attribution License, which permits unrestricted use, distribution, and reproduction in any medium, provided the original author and source are credited. 
approaches as, basic health determinants, which result to over stayed bodies to decompose. Majority of adults victims who die during the accident, lack national identity cards, which could be used as cold hits, from national DNA data base in the Central Bureau, whereby finger print stain impression by poroscopy in locard's method, is matched with a profile of persons on the database who are not suspects [1416], once identified, it is linked to I-24/7 communication network of INTERPOLs to report on the originality of the UCBOMDPs. As such, the study intend to use Police finger print forms to take finger prints impression, as double blind exposure to identify UCBOMDPs, from public mortuaries, using national data base from Central Bureau of Statistics, Kenya.

In investigating the trends uptake of community participation and empowerments for sustainable medico-legal approaches, through medico-legal laws and ethics utilization at community units, we observe and determine all necessary and sufficient roles played by next of kins, community units and crime police or police INTERPOL in applying signals codes 7 and 8, to identify UCBOMDPs promptly [17]. Synergistic community participation in forensic pathology forms hallmark of forensic science like other risk factors in the utilization of medico-legal concepts by multidisciplinary teams to provide, data evidence [6] such as identifying UCBOMDPs by using natural birth marks, writing statement before dissecting, in shared mutual responsibility and ownership among expertise of skilled teams [18], in which each person's responsibility is independent, but greatly attributed to the final causal/outcome in medico-legal process. Studies from SubSaharan Africa, indicate that community participation in medico-legal laws and ethics, requires synergistic participation [1], which provide and enhance appropriate technology and valid sustainable evidence in the diagnostic crime triangle (crime scene, history and death) [19]. However involvements of Kenyan communities, in the uptake of community participation in medico- legal laws and ethics, remains underutilized.

Capacity building in autopsy and embalming empowers health professionals and service providers with quality knowledge and skills as well as standards of operation, on how to perform embalming or autopsy procedures, [20]. However in western Kenya, provision of these necessary and sufficient human resource development and capacity building careers in fields of autopsy and embalming, remains underutilized and inefficient.

Studies by Haines shows that, human personality and the unconscious ego defence mechanism of service mortuary providers are influenced by Knowledge, Attitude and Practice (KAP), which may influence the program positively or negatively [20]. Studies by Hogg and Vaughan also show that, majority of community units effectively and efficiently achieve targets of their goals only if; their attitudes and perceptions on the program are positively powered by their inner emotions to achieve intended goals [21]. However, studies in western Kenya on how Knowledge, Attitude and Practice influence utilization of medico-legal approaches to identify (UCBOMDPs), remains unclear and unstated.

\section{Background iInformation}

Geographical location: Western Kenya Borders republic of Uganda to west and Rift Valley from north to south with its highest point being Mt. Elgon and lowest is Kisumu [22], Torrid Zone or Equator at Vihiga and Siaya Counties. Region covers an area of 25,302.7 km2 [23].

Population profile: Population health in western Kenya is
$11,488,949$ according to 2009 census [16] with life expectancy of 64years in males and 68years for females [11]. Annual population growth rate in region is 3.8 , with a higher fertility rate, attributed to low uptake of contraceptives among married couples [24]. Literacy rate in the region is $73 \%$ females and $70 \%$ males who attend primary, while $19 \%$ women and $13 \%$ men have limited education.

Health profile: Western Kenya contain over 490 public health facilities, excluding FBOS, NGOs, Privates and municipality facilities [25]. Includes for instance Moi, Jaramogi, Kakamega Teaching and Referral Hospitals, with mortuaries in full operational in substantial support from national medico-legal units [26]. Diseases burden prevalence in western Kenya is moderate, Calverton, (2009), in Malaria, Pneumonia, diarrhea, HIV/AIDs, intestinal worms, skin diseases, Upper respiratory tract infection, road traffic accidents and [13].

Social-economic profile: Western Kenya practice mainly agriculture, fish farming with strong industrial and commercial zones for employment to population health [16], Nyanza harbors tourist attraction zones such as Impala sanctuary, Kit Mikaye and Ndere island National park, Kakamega forest and the Crying stone," Blessing stone", in Kakamega, [23]. Majority of population are involved in manufacturing, fishing, food processing, and large scale rice, sugar cane and maize farming, tea, grain in farms, gold rush and soap carving at Tabaka in Kisii [27]. The Economic Recovery strategy (ERS) established 2003 by GOK, show that growth in western Kenya is declining towards the achievement of goal 4 (ERS) [16], that, aims to strengthen institutional governance. Poverty level in western Kenya stands $56 \%$ which makes it a fair far region in richness in Kenya.

Social-cultural profile: Western Kenya is cosmopolitan region of luhyas, Luos, kalenjins Kisii, Kikuyus and Tesos, majority of residents are Christians with Protestants being dominant denomination [16] Social-cultural status in western Kenya encourages mixed marriages and integration among different communities. However due to globalization and change in lifestyles, the region has witnessed various unwanted pregnancies, broken marriage and single marriages due to deteriorating traditional cultural virtues [26]. Existing diversity of cultural values in society makes it scarce and hard to estimate adult mortality rate. However mortality rates are lower in adulthood than childhoods who are estimated through vital records [24].

Specific objectives: 1 . To Investigate Trends uptake and Community Participation in Medico-legal concepts in Identification of UCBOMDPs from Public Mortuaries

2. To determine the level of Community Service Awareness and Empowerments in medico-legal concepts.

3. To determine How Knowledge, Attitude and Practice (KAP) of Mortuary Service Providers, Influence Identification of UCBOMDPs.

\section{Material and Methodology}

\section{Material}

Investigating trends uptake of community participation in medico-legal concepts in identification of UCBOMDPS

INTERPOL and police signal codes attribution in identification of UCBOMDPS: An international world Police organization (INTEROPL), forms the pillar of community participation in the fight against crime global, initiated INTERPOL's automated DNA data base and completed in 2013 [5] to maintain DNA data base of finger prints and DNA profile by allowing police of member countries, across 
Citation: Silali MB, Odero W, Rogena E (2017) Community Participation Medico-Legal Concepts to Identify Unclaimed or Missing Dead Bodies from Public Mortuaries to Improve Public Health in Western Kenya. J Health Med Informat 8: 260. doi: 10.4172/2157-7420.1000260

the world to make connection between crime and crime scene by submitting DNA profile from offenders, crime scene and UCBOMDPs [7]. The DNA gate way, as a tool of investigation was developed to fit international standards, to facilitate electronic transfer of DNA data between INTERPOL and its member countries who can access data via 1-24/7 global police communication system, which is extended to member country participation through National Central Bureau to forensic centres and laboratories. Selected international exports of DNA profiles use CODIS [28].

Police criminal signal codes are defined as one of the initial steps community participation in medico -legal laws and guidelines for admitting unclaimed body or "Brought in death patient" at Outpatients Department (OPD). In such scenario Police constables attached to the facility for forensic cases, use system of numbers to send message episodes for specific crime [7]. These are usually transmitted over the radio and one wait on line to give feedbacks. The aim of communicated signal codes 7 is to alert the community health on persons found missing in action, emergency health care or crime justice [14].

Crime signal codes and networks are commonly used by various uniformed security, CID agents in crime scene, 1-24/7 global police communication system assist identify terrorists and crime offender, through country members participation and' DNA national data base at Central bureau, in Kenya and may include; zero (0), one (1),two (2),three (3),four (4), five (5), six (6),seven (7), eight (8) and nine (9) signal codes. crime signal code zero $(0)$ is used to signify an armed person, one (1), drunk driver,(two) 2, drunken people, three (3), hit and run accident, four (4), accident with injuries, five (5), murder, six (6), escaped prisoner, seven (7), dead person, eight (8), providing feedback on unclaimed corpses, nine (9), lost or stolen license tags and ten (10), signifies stolen vehicles [15]. Despite regular empowerment and capacity building on the police signals and codes, during basic training, the effective and efficient function of code seven (7) and eight (8) remain underutilized as basic health determinants of medicolegal approaches in identification of UCBOMDPs from the public mortuaries, in western Kenya.

Adoption of health and local authority laws as medico-legal concepts: Medico-legal laws consist of health and local authority laws, which forms a bench mark of basic health determinants of medicolegal concepts and community participation to achieve the overall goal to identify UCBOMDPs, and are articulated clearly in the Public Health Act Cap 242, section 35-42, that provide reports and control of epidemics by quarantine and isolation, while section 144-148, provide procedures for community involvement in exhumation and disposal [19]. The Local Government Act, Cap 265, section 201, allows the local authority to regulate and formulate by-laws on the disposal of UCBOMDPs after 90 days [13]. The Human Anatomy Act Cap 249 prohibits illegal removal of any human body part without formal consent. The Human Tissue Act Cap 252 allows for the use of human body remains for therapy, medical education and research purpose, while the Criminal Procedure Code Cap 75, sections 386 and 387, allow Police Constables (PCs) to provide inquests on any medico-legal case (Appendix 1) [15].

However, observation studies in western Kenya demonstrate persistent skewed and limited community participation in health and local authority laws to identify UCBOMDPs from public mortuaries, thus the marked chemical, psychological and psychosocial hazards besides cumulating of UCBOMDPs on floors of public mortuaries. As such, the current study investigated community uptake in health and local authority laws as basic health determinant of medico-legal

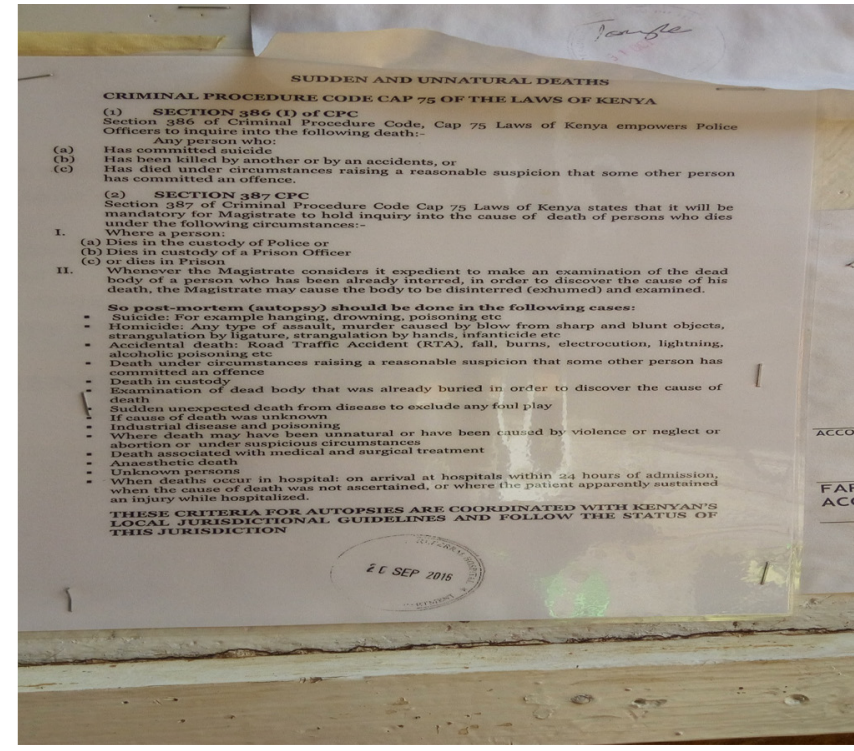

Source: (Tier 6 Facility Eldoret, 2016)

Appendix 1: Model of Medico and Health Law

concept in identification of UCBOMDPs from public mortuaries to improve health in Western Kenya.

Level of community awareness and empowerments in medicolegal laws in identification of UCBOMDPs public mortuaries

Mortuary service providers training in autopsy and medical ethics: Community participation in medico legal concepts enhance and provide the holistic analysis of what happened in the crime of triangle (History, Crime scene and Corpse) to cause sudden episode of the UCBOMDPs by interacting medico-legal laws, interrogating the immediate community unit or next of kins, the judiciary and crime police [4]. Medico-legal process- aims to protect and promote the basic human rights. Autopsy forms a fundamental episode of death investigations in the diagnostic crime triangle [19], and is geared towards establishing the time, manner and cause of death which may be natural or unnatural [7].

In Kenya most public mortuaries have functional cold rooms to keep unclaimed bodies or missing dead persons [14] as they wait for the proceeding medico-legal concepts that requires community participation, these includes, autopsy, court objection against burial and mass disposal. Since medico-legal laws and ethics overlap, risk managers liaises with other service providers, to ensure that health and local authority laws are correctly followed by the entire health population [29].

The Kenya Independent Medical Legal Unit (IMLU) protects and promotes the rights of tortured community, with public interest for litigation [7]. The IMLU advocates for the state of community awareness with holistic forensic application and utilization of the diagnostic crime triangle and capacity building of service providers, to practice quality medico-legal concepts while upholding the entire medical ethics [19] besides agitating for community empowerments to enhance sustainable medico-legal concepts. Medical ethics training for the health professions and service providers include-, ethical practices: autonomy (next of kin right to refuse or accept to consent for autopsy), beneficence (autopsy done on best interest of next of kin), non-maleficence (does not harm), justice, fairness and equality, dignity 
Citation: Silali MB, Odero W, Rogena E (2017) Community Participation Medico-Legal Concepts to Identify Unclaimed or Missing Dead Bodies from Public Mortuaries to Improve Public Health in Western Kenya. J Health Med Informat 8: 260. doi: 10.4172/2157-7420.1000260

(right to dignity), truthfulness and honest. However, in western Kenya, the level of community awareness and their trends uptake in autopsy procedures and utilization of medical ethics remain unclear.

Community empowering in quality embalming: Empowerment by definition is an idea of giving mortuary service providers; skills, resources, authority, opportunity and motivations as well as holding them responsible and accountable for the outcome of their actions, this contributes to their competence and complete satisfaction in medicolegal concepts [20]. Embalming which is defined in (Appendix 2-4) as a process to inhibit autopsy changes (purification by autolytic bacteria and Cathepsin enzymes) by recommended chemicals injected, through femoral artery of deceased under low pressure, so as to disinfect, preserve and fix the tissue organs [19]. Embalming preserves, and fixes tissue indefinitely to form mummification and saponification [7] and hence, forms a bench mark for primary prevention from the mortuary diseases and other associated mortuary health hazards [30,31].

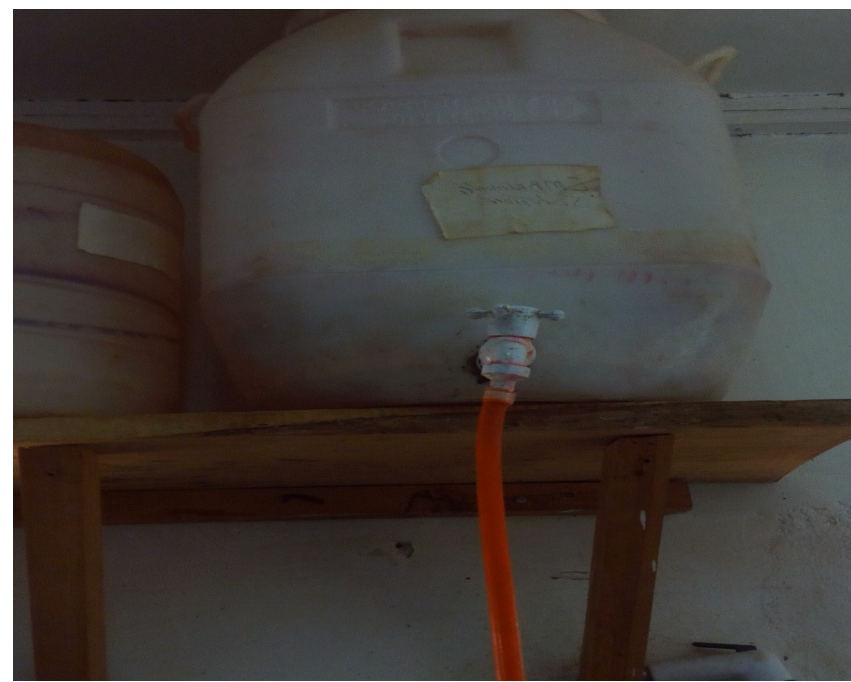

Appendix 2: Model of Embalming by Gravitation Method (Source: (Kitale County Facility, 2016))

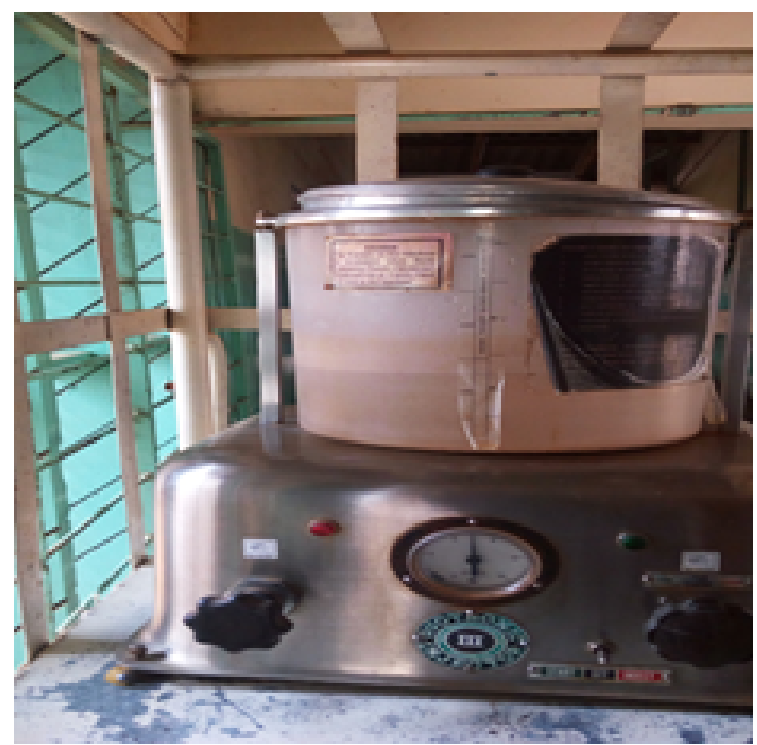

Appendix 3: Model of Modern Embalming Machine (Source: (Russia, Tier 6 Health Facility, 2016))

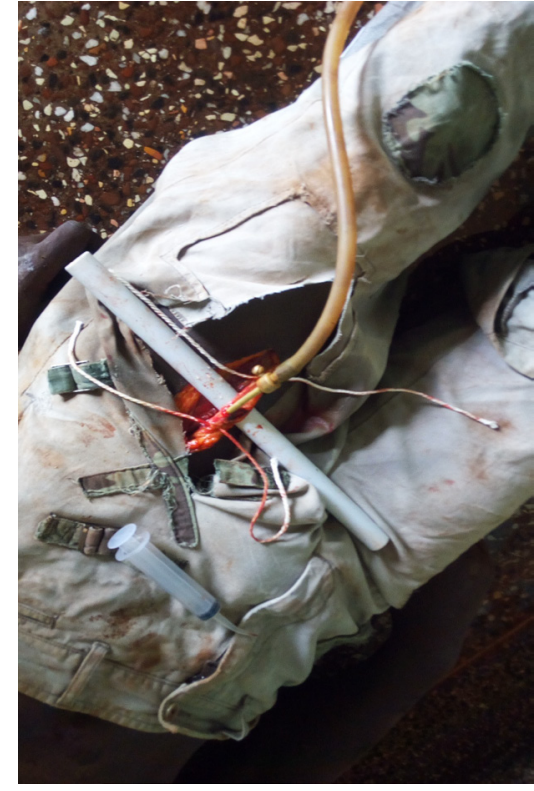

Appendix 4: Model of Modern Embalming by Arterial Puncture (Source: (Russia Tier 6 Facility, 2016))

Despite existing advocacy and on the state of community awareness on quality embalming programs as a way to eliminate or control most of mortuary disease and other associated health hazards, and the utilization of this medico-legal concepts as basic health determinants, remains ineffective and inefficiency for practical sustainability of public mortuaries in Western Kenya [25]. For these reasons, the current proposed study will determine level of capacity building and state of empowerments through training, influence quality, utilization of medico-legal approaches to identify UCBOMDPs from the public mortuaries.

Influence of knowledge, attitude and practice (KAP) of the community in identification of UCBOMDPs in our society: A number of studies by Haines show that, provision of appropriate technology, knowledge and skills in quality medico-legal concepts of the society are critical, and form the basis of sustaining zero incidence and spread of infectious diseases among community households [29]. Knowledge develops one's basic skills, and upholds innovative logic of understanding, through synergistic participation, planned in context of appropriate forensic technology, to enhance existing practical skills [1].

Studies by Hogg and Vaughan indicates that, a number of community units and mortuary service providers have gradually developed significant attitude of perceived bad or good feeling about medico-legal approaches thus reducing its implementation [2]. Bad attitudes, may impact negatively on society social controls and change, [9] on community implementation of medico-legal concepts as basic health determinants in the identification of UCBOMDPs from public mortuaries [32]. The World Health Organization (WHO) issued a joint statement on bad cultural practices, as a main health challenge facing the identification of UCBOMDPs, and has reduced the achievement of quality community appropriate technology in line with INTERPOL global forensic partnership for development, in the health sector [9]. As such, the study proposed intended to evaluate on how Knowledge, Attitude and Practice (KAP) of mortuary service providers and the community, influence identification of UCBOMDPs from public mortuaries in Western Kenya to improve health. 
High level of implementing medico-legal concepts, in identification of UCBOMDPs: The World Health Organization WHO reports demonstrate that, community participation in well implemented programs in basic health determinants are measured with specific scales of outcomes applied by mortuary service providers, to influence effective and efficient medico-legal results. Community implementation of the medico-legal laws in Kenya is higher in urban than rural health facilities.

A score $68 \%$ community implementation and above, signifies a positive impact on program goals and targets and are in line with MDGs 6 and 8 , MDG (2004), lower percentage of health outcome on basic health determinants of medico-legal concepts signify negative impact. High standards of community involvement in medico-legal concepts are measured by evaluating the holistic and comprehensive community implementation of the proposed study health risk factors prudently, and auditing their structural frameworks with functional measurable indicators with aim of eliminating or controlling the occupational health hazards, to maximize public health impact at the work place.

\section{Methodology}

Study area: Western Kenya (figure 1 below) covers $25,303.3 \mathrm{~km} 2$ with 2009 population census of $11,488,949$ population health,[3], and population Density of $454 / \mathrm{km}^{2}$. The region lies at longitude of $33 \mathrm{o}$ $37^{`} \mathrm{E}$ to $33055^{`} \mathrm{E}$, and latitude $108^{`} \mathrm{~N}, 1040^{`} \mathrm{~S}$. Facility on the highest altitude is Kitale County Hospital on northern, West is Busia County hospital, Bordering Uganda and Migori on lowest altitude on south bordering Tanzania. Siaya and Mbale County health facilities lie at the Equator [23]. Table I below demonstrates the main former counties that form public mortuaries in western Kenya that were used to for data collection on medico-legal approaches.

\begin{tabular}{|c|c|c|c|c|}
\hline Code & County & Area/km & 2009 Census & Capital \\
\hline 26 & Trans-nzoia & 2469.9 & 818,757 & Kitale \\
\hline 27 & Uasin Gishu & 2955.3 & 894,179 & Eldoret \\
\hline 37 & Kakamega & $3,033.8$ & $1,660,651$ & Kakamega \\
\hline 38 & Vihiga & 531.3 & 554,622 & Mbale \\
\hline 39 & Bungoma & 2206.9 & 1375,063 & Bungoma \\
\hline 40 & Busia & 1628.4 & 742,966 & Busia \\
\hline 41 & Siaya & 2496.1 & 842,304 & Siaya \\
\hline 42 & Kisumu & 2009.5 & 968,909 & Kisumu \\
\hline 43 & Homa Bay & 3154.7 & 963,794 & Homa Bay \\
\hline 44 & Migori & 2586.4 & 917,170 & Migori \\
\hline 45 & Kisii & 1317.9 & $1,152,282$ & Kisii \\
\hline 46 & Nyamira & 912.5 & 598,252 & Nyamira \\
\hline Total & & $\mathbf{2 5 3 0 2 . 7}$ & $\mathbf{1 1 , 4 8 8 , 9 4 9}$ & \\
\hline
\end{tabular}

The determination of the basic health risk factors of medico-legal approaches in identification of UCBOMDPs from public mortuaries to improve Public health in western Kenya was carried out in public health facilities of tiers, 4, 5 and 6, located in administrative and political map unit below where medico-legal approaches were initiated, and being utilized, to identify the UCBOMDPs [25]. Although a total numbers of public health facilities in western Kenya are over 490, only 20 health facilities met threshold of being inclusion criteria, (participating in medico-legal approaches with the structural support from National medico-legal unit (Map 1).

Study design: Study used cross-sectional and exploratory designs where insights of investigations and exposures of sampled respondents and their outcome are measured at same time respectively to determine levels of basic health determinants of medico-legal approaches in identification UCBOMDPs from public

\section{Distribution of Gender in Mortuary Service Provision}

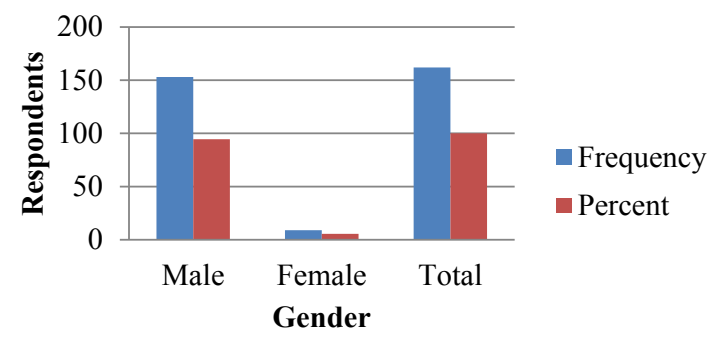

Figure 1: Demonstrate the Proportion of community participation in mortuary service by gender.

\begin{tabular}{|c|c|c|c|}
\hline Signal utilization & No .of case utilized & No. of cases not utilized & Total \\
\hline Detective Police & 4 & 12 & 16 \\
\hline Morticians & 11 & 158 & 169 \\
\hline
\end{tabular}

Table 1: Above indicate prevalence of Detective and Morticians participation in conveying Police Signal codes as one of medico legal concepts.

mortuaries in western Kenya. Quantitative data was collected by formal survey using a structured questionnaire on service providers and Police finger print forms were used to take finger prints from UCBOMDPs in cold rooms, as double blind test in the national DNA data base. In qualitative survey, exploratory design was used to collect data on insights of investigations, using a focused group discussion (FGD) guide and Key Informants interviews (KII) with mortuary service providers. In observation 3Ls (look listening and learn) tools were exploited during transect mapping, with help of observation checklist to gather medico-legal information.

Study population: Study was purposive to majority of mortuary service providers and health professional attached to provide services into mortuaries besides double blind finger prints testing on UCBOMDPs lying in public mortuaries during the survey period. Mortuary service providers and health professions involved in the study were: Death investigators, Police officers, police wardens, and crime scene investigators, liaison managers, coroners/medical examiners, pathologists, forensic technologist, forensic anthropologists, and forensic odontologists, administrators, Community-Owned Resource Persons (CORPs).

Inclusion criteria: All service providers and health professions, who have worked for more than three months in a health facility or mortuary and attached to issues affecting medico-legal approaches, as basic health determinants in identification of UCBOMDPs from public mortuaries to improve public health in Western Kenya, were used as target population. Unclaimed bodies or missing dead persons aged above 18 months were also targeted in the general evaluation and facilities had memorandum of understanding to participate in medico-legal approaches with the structural support from National medico-legal unit.

Exclusion criteria/limitation of study: We do acknowledge certain limitations of this study that our findings and results of this study were based on respondents who provided in any way mortuary services to public mortuaries and finger prints of the 73 UCBOMDPs found lying in public mortuaries in western Kenya during the period of our six months study (July 2016 to February 2017 ). Service providers and health professions, whose services delivery are not related to medicolegal approaches, like UCBOMDPs found aged below 18 years were not sampled in the double blind study, since; they lack a copy national identity card to be traced in National data base bureaus. 


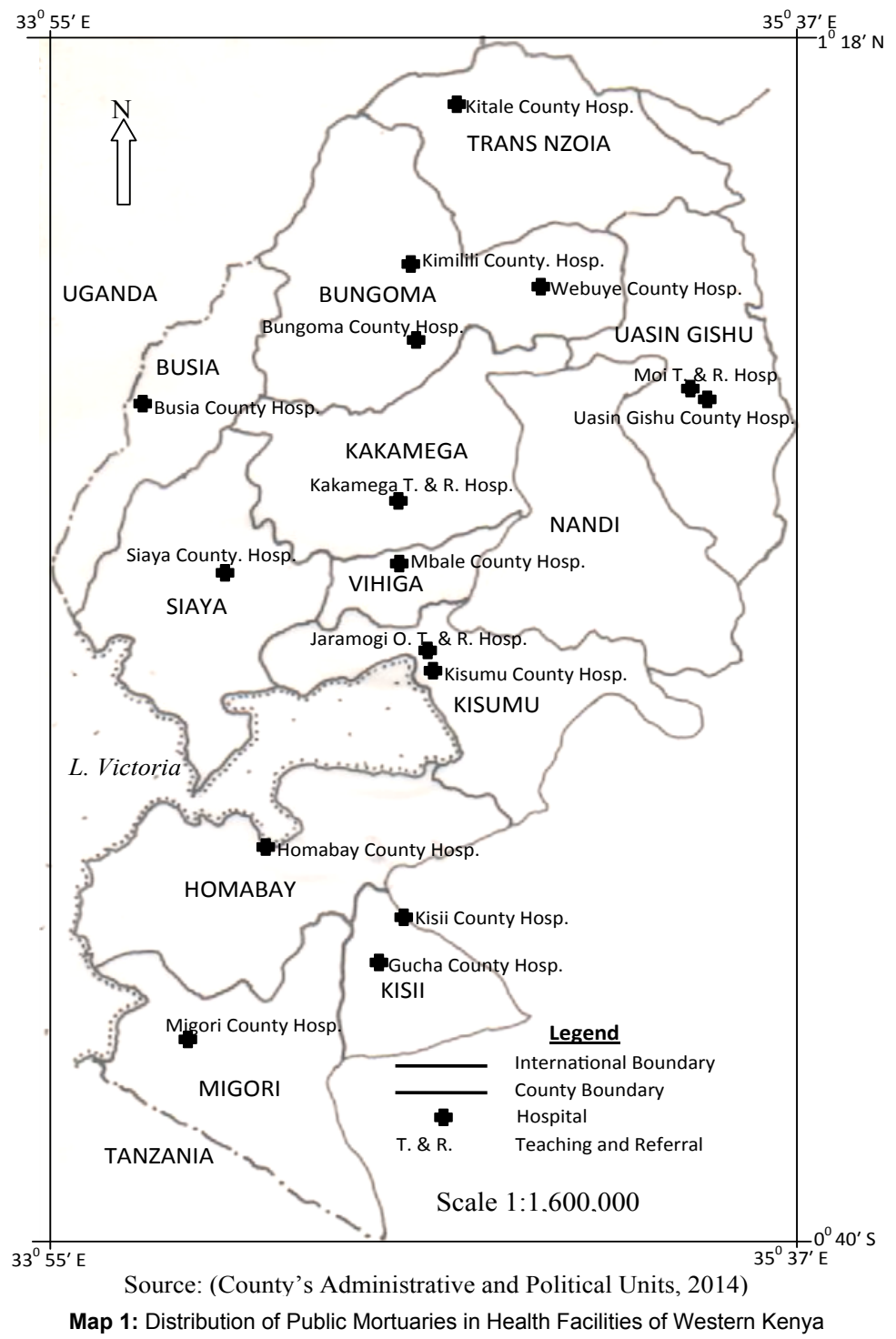

There was also possibility of response bias by detective, police warden or morticians during body admission in the morgue or during data collection, to provide wrong responses or some data may be missed out during cleaning process. Also recall bias was bound to occur during interviews in the explorative discussions, in FGD and KII.

Sampling design: Saturated purposive sampling designs were utilized to select and determine the study subjects basing on specific research question. A sampling frame was developed from mortuary service providers. The facility was evaluated based on opinions of key informants and on the total number of service provider in relation to UCBOMDPs present at that point in time. Questionnaires and police finger print forms were administered, to the pre-trained personnel and corpses respectively. Upon entry into a health facility, mortuary service providers or health profession were asked to draw a list of staff present and those of unclaimed bodies or missing dead persons admitted by detective/warden Police. Demographic data were recorded and fingerprint stain impression taken using a roller-bad and black ink, then transferred onto a police finger print form. This process was carried out until the required sample size of 73 finger prints was obtained.
For qualitative, focus group discussion FGD and key informant interview KII, questionnaires guides were administered, explored and sub themes were discussed to saturation with all mortuary Service providers' health professional respectively. Transect mapping and observation by listening, learning and looking on other related basic health determinants of medico-legal approaches provided vital information not captured before, by the chief researcher questionnaires.

Sample size determination: Sample size was determined by Fisher formula [6] and adjusted by finite formula in twenty (20) public health facilities implementing medico-legal concepts to identify UCBOMDPs public mortuaries in the estimated target population of 600 respondents.

Fisher's formula states:

$n=\frac{Z^{2} p q}{d^{2}}$

Where

$\mathrm{n}=$ target population greater than 10,000 


\section{$\mathrm{Z}=$ degree of confidence (1.96)}

$\mathrm{p}=$ Population of estimated study / target population (0.50)

$\mathrm{q}=$ proportion of the acceptance proportion significance of respondents estimated to be traced. $(0.50)$

$\mathrm{d}=$ level of statistical test, 0.05

$$
\begin{aligned}
& n=\frac{(1.96) 2(0.5)(0.5)}{(0.05) 2} \frac{9604}{25} \\
& \mathrm{n}=384
\end{aligned}
$$

Adjustment of the sample size was done, using Finite population correction formula (Fisher's 1998) because estimated sample size from public health facilities in western Kenya was below 10,000 respondents.

Hence corrected sample size:

$$
n f+\frac{n}{1+\left(\frac{n}{N}\right)}
$$

Where

$$
\mathrm{nf}=\text { desired sample size of respondents was less than } 10,000 \text {. }
$$

$\mathrm{n}=$ desired sample size of respondents was more than 10,000

$\mathrm{N}=$ total estimated study/target population size (600)

Hence:

$$
\begin{aligned}
& n f \quad \frac{384}{600} \\
& 1+\frac{\{384\}}{600}
\end{aligned}
$$

$=235$ respondents

The number of samples, from each facility was purposively saturated based on number of mortuary service providers deployed and UCBOMDPs present in the sampling frame during that period of study.

Selection and training of research assistant and enumerators: Twenty research assistants and forty enumerators were trained on interview techniques, counselling, data collection, recording and handling. All unforeseen challenges likely to come up during the exercise were addressed in a de-briefing workshop, organized at the end of every event. The research assistants included CORPs, hospital administrators and PHOs, who from time to time implement medicolegal concepts. The enumerators were mortuary in-charge and morticians who will from time-to-time; visit the mortuary premises to participate in sampling.

Field data collection: Field data collection team comprised of; one team leader who was principal investigator, 20 research assistants and 40 enumerators, the team was divided into three groups, based on the site of the facility they are working from in order to facilitate answering questionnaires, (KII) and (FGD) discussions. The supervisor of the team upon arrival at the facility was introduced to the person in-charge of the facility to explain the purpose of the study in order to obtain consent. Consent was obtained from each respondent, before questionnaires were distributed. After consenting, 12 respondents were chosen at random using 'Yes' and 'No' papers for FGD discussion, if the facility has more than 12 respondents. After completing the entire task for each facility, the study team reviewed their filled tools to ensure its completeness and then summarize before proceeding to the next facility.
To ensure that quality data was collected, the principal investigator was involved throughout the entire process of data collection. This was purposely to ensure completeness, consistency, and accuracy in data collection, with challenges experienced during data collection being discussed at the end of each day.

Pre-testing of tools: Data collection tools were pre-tested in Busia county facility to ensure reliability, validity and suitability of questionnaire. Filled questionnaires and finger print forms checked and correction were made accordingly.

Questionnaire: Quantitative, exploratory design was used to capture data through survey and interviews, by administering questionnaires, Interview and focus group discussion guides. Information to obtained during investigation included, demographic profiles, pathways of DNA fingerprint test, community uptake with medico-legal concepts, influence of capacity building and empowerments of communities in the implementation of medico-legal concepts and influence of partnership in medico-law and ethics, influence of health laws, forensic training/embalming and effect of knowledge, attitude and cultural practice (KAP) in the identification of UCBOMDPs in public mortuaries.

\section{Key informants interview (KII) guide}

Key informants were administered to those in-charges of health facility, mortuary or public health officer and detective police. The KII guide tailored to suitable respondents who implement or utilize medico-legal concepts in the community health.

\section{Focus group discussion (FGD)}

A structured group guide was formulated to gather information on knowledge, attitude and practice of both mortuary providers and other health professionals in participation, towards the utilization of the basic health determinants of medico-legal concepts in delivery of quality health care. Each (FGD) composed of 3 to 12 representative discussants, selected based on their gender, age, experience, skills, level of education and appropriate technology acquired from each 20 facilities of study. This was to ensure homogenous, free, fair and active participation. Discussions were moderated by the lead researcher, while research assistants observed body language and take notes during the discussion.

\section{Transect walk and observation check list}

Observation check list provided the guide in investigation and observation in a walk-through survey, in facility by principal investigator. This will provide information on spatial infrastructure, serviceability of embalming and cold room equipment, data filing system availability and disposal of human waste in line with public health standards.

\section{Results and Findings}

During our study on community synergistic participation to deliver quality mortuaries services in western Kenya, 235 respondents of were used in exploratory and cross sectional designs of mixed research in purposive and saturated sampling designs to collect data, through survey and interview using FGDs, KIIs and observation guides, whereby. $70 \%$ (162) respondents with a mean of 1.06 , with deviation of 0.23 , were mortuary service providers and 30\% (73) were (UCBOMDPs) finger prints impression,( Blueprint for dead bodies, sort of an instruction manual that contains genetic information), which were traced in CID headquarters for comparison studies, using magnifying lens, 
Citation: Silali MB, Odero W, Rogena E (2017) Community Participation Medico-Legal Concepts to Identify Unclaimed or Missing Dead Bodies from Public Mortuaries to Improve Public Health in Western Kenya. J Health Med Informat 8: 260. doi: 10.4172/2157-7420.1000260

Page 8 of 11

comparator machines or Automated Biometric Identification Systems (ABIS). Gender, social expression of a person's identity in relation to social role and behaviour results indicated that majority $94 \%(153)$ of mortuary service providers with mean of 5.33 and STD deviation of 1.47 , were males, with Spear man correlation value of 0.315 . Males had limited knowledge on basic mortuary science compared to $6 \%$ (9) female counterparts' mortuary with good knowledge on standard operating procedures (SOPs) on quality medico - legal concepts to improve public health.

It is revealed from our study that community participation in solving DNA profile offenders, crime scene and UCBOMDPs, forms a bench map for quality investigation and identification services, which also assist to develop Automatic Biometric Identification systems of DNA data, that is interlinked between INTERPOL and its member countries who access data via 1-24/7 global police communication system, which is extended to member country via National Central Bureau to forensic centres and laboratories. However from the study we discovered western Kenya has no such existing good linkages of Automatic Biometric Identification System to influence positive significance on the utilization of medico-legal approaches within its region.

During our interrogation also with one of DCIO in CID from western Kenya, we found out that though the police learnt utilization of police signal codes seven (7) and eight (8) in recruit training school on events of UCBOMDPs in order to partner with community households, in conveying message, we discovered that, its application is still underutilized, due to over stretched limited resources and poor linkages of community participation in communication between national and county governments. The study realized that $67 \%$ (12) out of 20 detective police attached to public mortuary to assist investigate issues of UCBOMDPs in the region, do not know on how to utilize signal 7 and 8 efficiently. While only 6\% (11) morticians were discovered to correctly utilize codes in partnership with next of kins or family friends to alert the family member on issues related to (UCBOMDPs).

In our study in the region, we also established existence of mutual synergistic participation and positive significance among morticians, detective police and other mortuary service providers in implementing some of medico-legal approaches such as Penal Code 75, local authority Act, Cap 365 and Public Act Cap 242.with RR (3.8), with 95\% CI (3.34), attributed to positive significance of implementing medicolegal approaches.

Medico-legal approaches are constitutional measurable variable in the laws of Kenya, includes Medico-legal laws consist of health and local authority laws, and are articulated clearly in the Public Health Act Cap 242, section 35-42, that provide reports and control of epidemics by quarantine and isolation, while section 144-148, provide procedures for exhumation and disposal. The Local Government Act, Cap 265, section 201, allows the local authority to regulate and formulate bylaws on the disposal of UCBOMDPs after 90 days, while the Criminal Procedure Code Cap 75, sections 386 and 387, allow Police Constables (PCs) to provide inquests on any medico-legal investigation. Studies in western Kenya on adoption of medico-legal laws by public health facilities revealed that, majority $80 \%$ (16) out of 20 public facilities like mortuary service providers whom we surveyed and interviewed felt that, have limited knowledge on integrated medico-legal linkages attributed to health management of UCBOMDPs in the public health sector.
The study discovered that mortuary service providers are involved in community diagnosis, statement, ante mortem process, writing statement and assist pathologist or medical officers to perform autopsy.

The study of Forensic pathology in our modern health facilities contemplate the purpose to protect and promote the basic human rights in our society, ante mortem and autopsy form pillar episodes for unclaimed or missing presumed dead persons' to start being investigated from the diagnostic crime triangle (History, Crime scene and Corpse) and are geared towards establishing the time, manner (natural, accident, suicide, homicide, or undetermined), and the actual cause (disease, injury or abnormality) of death. However, if a death occurs under suspicious circumstances, it's the responsibilities of state to override the wishes of the family and may order a post-mortem without seeking permission from the deceased's relatives. In the study area it was revealed that, most $65 \%$ (13) out of 20 public mortuaries surveyed have non- functional cold rooms to keep unclaimed bodies or missing dead persons waiting for proceeding medico-legal approaches, (ante-mortem, autopsy, court objection against burial and mass disposal).

Non-functional cold rooms in public mortuaries of western Kenya promote petrifaction processes and increase the rate of Cathepsin enzymes, thus increasing rate of decay and persistence foul smell, which are health nuisance to the health population. When the relevant antemortem information on a missing person has been gathered and the data has been collected on the found human remains, the next step of the identification process begins. During the study in public facilities in western Kenya on capacity building in order to ascertain ability of morticians to maintain basic standards of sanitation and hygiene, we discovered that majority 74\% (120) out of 162 morticians are Primary and Secondary school leavers with limited knowledge on both public health and forensic science, however they obtained in house training through on job bench training.

The study also realized though majority $85 \%$ (17) out of 20 facilities surveyed and interviewed Public Health Officers (PHO) attached to public mortuaries in western Kenya, (to implement CAP 242 of Public act and CAP 265 of Local Authority Act). Thus only prepare mass disposal and improve the general sanitation and hygiene in public mortuaries. However in reality PHOs have limited knowledge on holistic utilization of medico- legal approaches in the health sector as realized in discussions group.

Study also established that these vital Health laws and other medico-legal approaches are hidden from communities in our society, hence, form key reasons to be sensitize to community households using social media and other forms of dissemination.

In our the study on medico - legal approaches in health facilities it is revealed that, embalming is process to inhibit autopsy changes (peutrification by Autolytic bacteria and Cathepsin enzymes) by recommended chemicals injected, through femoral artery of deceased under low pressure, so as to disinfect, preserve and fix the tissue organ. Embalming preserves, and fixes tissue indefinitely to form saponifications, mummification, and the process is achieved through various methods. During our study in public mortuaries of western Kenya we discovered that majority of facilities 97\% (17) utilize gravitation methods of embalming, while only $3 \%$ (3) facilities namely': Moi referral, Kakamega and Jaramogi Odinga referral use modern embalming machines. Prevalence of estimated risks associated with embalming by the gravitation method through gross infection and other health hazards encountered such as prolonged inhalation of 
mortuary chemicals by morticians or embalmers, were high compared to those using embalming machine with, OD $(3.33,1.24), 95 \%$ CI ( $2.3,1.33)$. Statistics on quality embalming using pulsating Embalming machines had a lower relative risks RR, (0.35), with significance of protective measures to mortuary service providers.

During our the study in public mortuaries of western Kenya we realized that, Knowledge develops one's basic skills, and upholds his or her innovative logic of understanding, through synergistic participation planned in context of appropriate forensic technology to enhance existing practical skills and also boost the social economic lives of communities and the society.

Study in facilities of western Kenya, we established that utilization of medico-legal approaches in public mortuaries are influenced differently depending on Knowledge, Attitude and Practice of health managers and mortuary service providers, for instance facilities where the MOHs take lead roles to recognize the attributes of maintaining basic health standards of sanitations and hygiene in morgue like in surgical wards, they do it synergistically involving most of other stakeholders and mortuary service providers thus, adopt their knowledge, attitudes and practices comprehensively towards improving and maintaining the achievement of set targets on basic sanitation and hygiene.

\section{Discussion}

It is revealed from the study by the Interpol [5], that DNA profile from offenders, crime scene and UCBOMDPs, forms a bench map for DNA investigation and identification pillar, which also assist to develop Biometric Identification systems of DNA data, that is interlinked between INTERPOL and its member countries who access data via 1-24/7 global police communication system, which is extended to member country via National Central Bureau to forensic centres and laboratories. However from the study we discovered western Kenya has no such existing linkages of live Biometric identification system to influence positive significance on the utilization of medico-legal approaches within its region. This is quite contrary with studies by [33] on History and holistic development of forensic science in India and study by [31] on Health challenges that are influenced by bad health practices which forms major difficulty in achieving quality healthcare in developing countries.

During our interrogation also with one of DCIO in CID from western Kenya, we found out that though police learnt utilization of police signal codes seven (7) and eight (8) in recruit training school on events of UCBOMDPs in order to partner with community households, in conveying message, we discovered that, its application is still underutilized, due to over stretched limited resources and existing poor linkages of communication between national and county governments. The study realized that $67 \%$ (12) out of 20 detective police attached to public mortuary to assist investigate issues of UCBOMDPs in the region, do not know on how to utilize signal 7 and 8 efficiently. While only $6 \%$ (11) morticians were discovered to correctly utilize codes in partnership with next of kins or family friends to alert the family member on issues related to UCBOMDPs which is in line with the study by [1], on importance of synergistic participation of community household to influence sustainable programs in our society.

In our study in the region, we also established existence of mutual synergistic participation and positive significance among morticians, detective police and other mortuary service providers in implementing some of medico-legal approaches such as Penal Code 75, local authority Act, Cap 365 and Public Act Cap 242.with RR (3.8), with 95\% CI (3.34), attributed to positive significance of implementing medico-legal approaches, and study is similar to study by [6] on mutual attributes of community participations in medico-legal approaches to influence empowerments and sustainability of the facility programs.

Medico-legal approaches are constitutional measurable variable in the laws of Kenya, includes Medico-legal laws consist of health and local authority laws, and are articulated clearly in the Public Health Act Cap 242, section 35-42, that provide reports and control of epidemics by quarantine and isolation, while section 144-148, provide procedures for exhumation and disposal. The Local Government Act, Cap 265, section 201, allows the local authority to regulate and formulate bylaws on the disposal of UCBOMDPs after 90 days, while the Criminal Procedure Code Cap 75, sections 386 and 387, allow Police Constables (PCs) to provide inquests on any medico-legal investigation. Studies in western Kenya on adoption of medico-legal laws by public health facilities revealed that, majority $80 \%$ (16) out of 20 public facilities like mortuary service providers whom we surveyed and interviewed felt that, have limited knowledge on integrated medico-legal linkages attributed to health management of UCBOMDPs in the public health sector which contrary to, [11] on guideline on crime analysis and subject dissemination in health sector.

The study discovered that mortuary service providers are involved in community diagnosis, statement, ante mortem process, writing and assist pathologist or medical officers to perform autopsy which is in line with the study by $[1,7]$,on outlines on community participation in medico-legal approaches to enhance empowerments and sustainability of SOPs in the laboratories.

The study of Forensic pathology in our modern health facilities contemplate the purpose to protect and promote the basic human rights in our society, ante mortem and autopsy form pillar episodes for unclaimed or missing presumed dead persons' to start being investigated from the diagnostic crime triangle (History, Crime scene and Corpse) and are geared towards establishing the time, manner (natural, accident, suicide, homicide, or undetermined), and the actual cause (disease, injury or abnormality) of death. However, if a death occurs under suspicious circumstances, it's the responsibilities of state to override the wishes of the family and may order a post-mortem without seeking permission from the deceased's relatives. In the study area it was revealed that, most $65 \%$ (13) out of 20 public mortuaries surveyed have non- functional cold rooms to keep unclaimed bodies or missing dead persons waiting for proceeding medico-legal approaches, (ante-mortem, autopsy, court objection against burial and mass disposal).

Non-functional cold rooms in public mortuaries of western Kenya promote petrifaction processes and increase the rate of Cathepsin enzymes, thus increasing rate of decay and persistence foul smell, which are health nuisance to the health population. When the relevant antemortem information on a missing person has been gathered and the data has been collected on the found human remains, the next step of the identification process begins. During the study in public facilities in western Kenya on capacity building in order to ascertain ability of morticians to maintain basic standards of sanitation and hygiene, we discovered that majority $74 \%$ (120) out of 162 morticians are Primary and Secondary school leavers with limited knowledge on both public health and forensic science, however they obtained in house training through on job bench training. These findings are contrary with the study by $[7,30]$, on quality of standard operating procedures and principles 
Citation: Silali MB, Odero W, Rogena E (2017) Community Participation Medico-Legal Concepts to Identify Unclaimed or Missing Dead Bodies from Public Mortuaries to Improve Public Health in Western Kenya. J Health Med Informat 8: 260. doi: 10.4172/2157-7420.1000260

Page 10 of 11

of embalming, training and qualifications for human resources to perform quality embalming and assist in autopsy work.

The study also realized though majority $85 \%$ (17) out of 20 facilities surveyed and interviewed Public Health Officers (PHO) attached to public mortuaries in western Kenya, (to implement CAP 242 of Public act and CAP 265 of Local Authority Act). Thus only prepare mass disposal and improve the general sanitation and hygiene in public mortuaries. However in reality PHOs have limited knowledge on holistic utilization of medico- legal approaches in the health sector which is in line with the study by [20], on Human resources for health: overcoming the crisis in the developing countries.

Study also established that these vital Health laws and other medico-legal approaches are hidden from communities in our society, hence, form key reasons to be sensitize to community households using social media and other forms of dissemination.

In our the study on medico-legal approaches in health facilities it is revealed that embalming inhibit autopsy changes, preserves, and fixes tissue indefinitely to form mummification and saponification of oil to form fats. During our study in public mortuaries of western Kenya we discovered that majority of facilities $97 \%$ (17) utilize gravitation methods of embalming, while only 3\% (3) facilities namely': Moi referral, Kakamega and Jaramogi Odinga referral use modern embalming machines. Prevalence of estimated risks associated with embalming by the gravitation method through gross infection and other health hazards encountered such as prolonged inhalation of mortuary chemicals by morticians or embalmers, were high compared to those using embalming machine with, OD $(3.33,1.24)$, the study is contrary to study by [30] on statistics on quality embalming using pulsating machines had a lower relative risks RR, (0.35), significance of protective measure achieved, also the investigations are not keeping in line with the study by [19] which advocate for vital roles attributed with utilizing the modern embalming machine to achieve quality public service delivery for the health population.

During our the study in public mortuaries of western Kenya we realized that, Knowledge develops one's basic skills, and upholds his or her innovative logic of understanding, through synergistic participation planned in context of appropriate forensic technology to enhance existing practical skills and also boost the social economic lives of communities and the society.

Study in facilities of western Kenya, we established that utilization of medico - concepts in public mortuaries are influenced differently depending on Knowledge, Attitude and Practice of health managers and mortuary service providers, for instance facilities where the $\mathrm{MOHs}$ take lead roles to recognize the attributes of maintaining basic health standards of sanitations and hygiene in morgue like in surgical wards, they do it synergistically involving most of other stakeholders and mortuary service providers thus, adopt their knowledge, attitudes and practices comprehensively towards improving and maintaining the achievement of set targets on basic sanitation and hygiene, these findings are in line with study by Kenya Service Provision Assessment [26], on the influence of culture and beliefs by Kenyan communities to achieve focused target based on set goals, and also research is similar to study by who demonstrated the importance of synergistic community participation to provide empowerment and sustainable programs in our society.

\section{Conclusion}

Our findings indicates that, Community participation in medico- legal concepts, in identification of unclaimed or missing dead bodies presumed death in western Kenya to improve health, remains skewed, limited and inaccessible, due to prolonged existing limited resources to advocate for accessible quality synergistic partnership models among diversity of communities in our society (Caption 1-5), and limited access to advocacy on medico-legal knowledge at household level as one of the approaches in holistic and comprehensive health promotion and health education in our society (Figure 1-4). Constant decline in medico-legal communications and networking on quality utilization of medicolegal concepts remain a big challenge to be addressed through informed policy change and development (Table 1).

Identify the body and remove from cold room in partnership with the next of kin , place on trolley and recall more family member to confirm by viewing, and re identify. Break the : rigomortis, disinfect, take finger prints or embalm or start autopsy process. Result for finger print allow next of kin to go court to take oath, call members who came to witness autopsy to give them preliminary report of your findings. On the day of discharge, call them to confirm name of the deceased write burial permit, allow them to go make payment of mortuary bills as you dress the corpse assist them to put in coffin then discharge. FGD discussion in Tier 5 facility in Kisumu county on 17.11.2016".

Caption 1: Demonstrate the role of community participation in identification of UCBOMDPS.

Police signal codes remain underutilized as basic health determinants of medico-legal approaches in identification of UCBOMDPs from the public mortuaries due to limited resources and other police logistics in the department KII interview with DCIO from CID headquarter 2312017.

Caption 2: Demonstrate how some of medico-legal concepts remains inaccessible and underutilized in our society.

"The only two laws which most of PHOs we are aware of is Public Act Cap 242 and Local Government Act, Cap 265, other laws may they our formulated recently," KII discussion with PHOs in Homabay and Kitale Health facilities on 18 and $21-11-2016$

Caption 3: Demonstrate the need to have integrated human resource to implement quality mortuary service.

I believe health laws and Public health laws are only closed to pathologist and Public health officers they need to be taught to all service providers doing medical courses. FGD discussion with morticians in Bungoma County Facility mortuary on 22.11.2016

Caption 4: Demonstrate the consistence limited access to medico-legal concepts to empower the society in quality participation.

"We strongly feel that we are neglected in mortuary by our $\mathrm{MOH}$ fraternity in Kisii,, we have no gloves, no electricity in cold room, no embalming machine, no gravitation method, even water sometime, "FGD. discussion in Kisii facility on 23.112016

Caption 5: lindicate extent of limited participation in medico-legal concept by some of health stockholders in the study area.

"Here in Eldoret Prof, Gosloff and Dr. Gosloff build positive knowledge, attitude and functional practice on quality mortuary service management which we always look forward to maintain as mortuary community" KII interview in Tier six facility in Eldoret on 20/11/2016.)

Caption 6: Demonstrate importance of community empowerment in sustaining community programs in our society. 
Citation: Silali MB, Odero W, Rogena E (2017) Community Participation Medico-Legal Concepts to Identify Unclaimed or Missing Dead Bodies from Public Mortuaries to Improve Public Health in Western Kenya. J Health Med Informat 8: 260. doi: 10.4172/2157-7420.1000260

Page 11 of 11

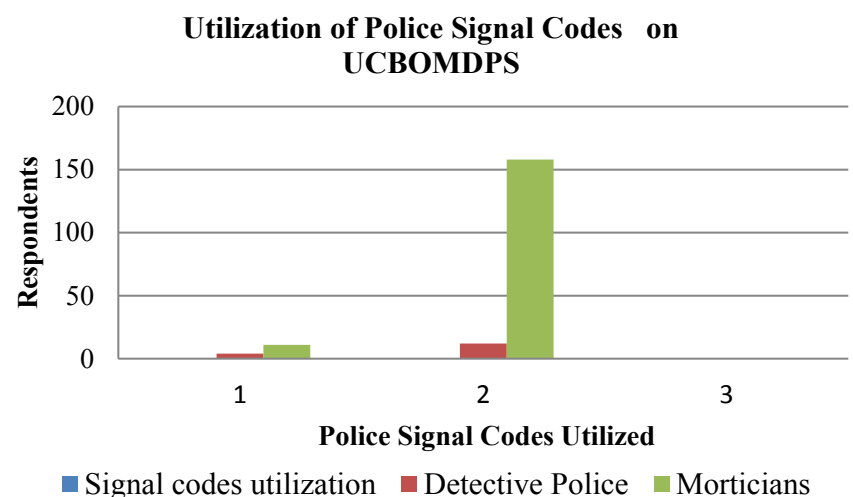

Figure 2: Proportion of Mutual Synergistic Participation among Morticians, Detective Police and other Mortuary Service Providers in implementing medico-legal concepts.

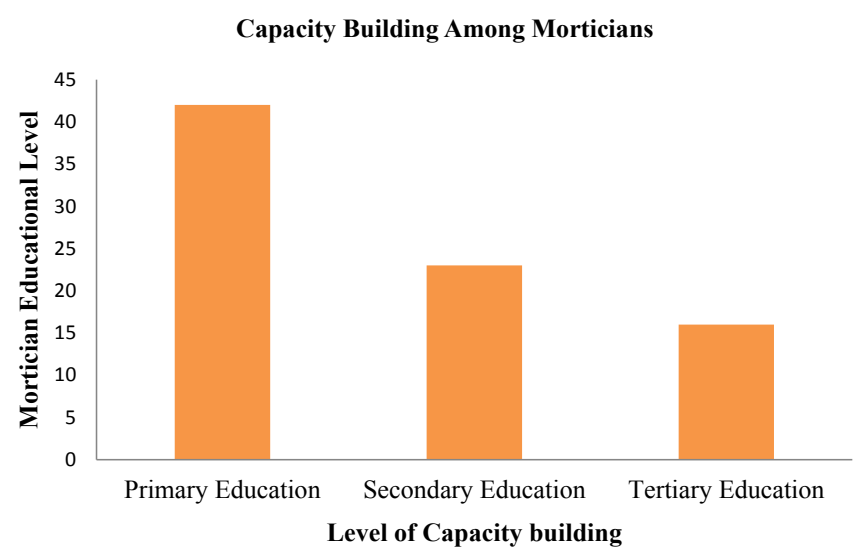

Figure 3: Indicate Level of Capacity Building on Quality Skills and Knowledge on mortuary Science.

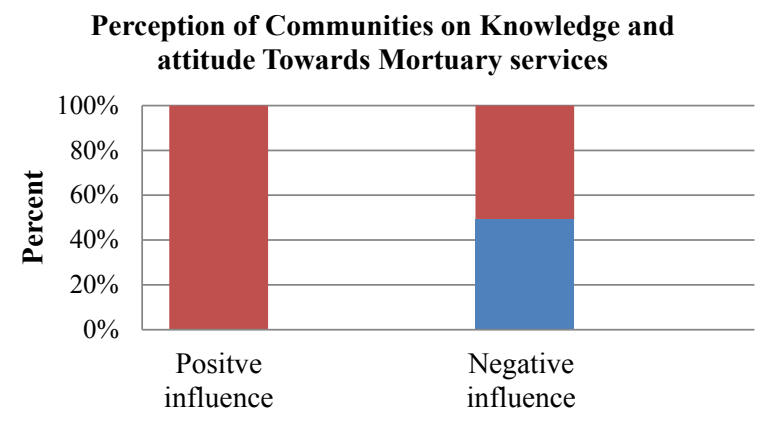

Level of Influence

Figure 4: Proportion of Community Perception on how Knowledge and Attitude Influence Implementation of quality Medico- legal approaches.

\section{References}

1. Southerland (1998) Participation Research in Natural resources, socialeconomic, Trainer's Guide for Participatory learning and Action, London.

2. Kindig D, Asada Y, Booske B (2008) A Population Health Framework for Setting National and State Health Goals. JAMA 299: 2081-2083.

3. Risinger DM, Saks MJ, Thompson WC, Rosenthal R (2002) The Daubert / Kumho Implications of Observer Effects in Forensic Science: Hidden Problems of Expectation and Suggestion. Californ L Rev 90: 1-56.

4. Interpol (2009) Interpol DNA Hand Book
5. Interpol (2015) Criminal intelligence analysis.

6. Fisher's (1998) Sample size determination and Finite population Correction formulae.

7. Olumbe (2002) Hand book of text book of forensic medicine and medical legal in Kenya.

8. WPD (2012) World Population Data: National master data, World population references bureau.

9. MDG (2004) Millennium Development Goals for health: Rinsing to challenges, combating environment health to improve basic sanitation and hygiene, progress report; Washington DC and World Bank.

10. Evans R, Stoddart GC (1990) Producing Health, Consuming Health Care. Soc Sci Med 31: 1347-1363.

11. IUCR (2012) Inter University Research Council: Challenges facing people living in torrid zones and effort to improve their lives and environment.

12. Interpol (2011) INTERPOL DNA Search Request Forum.

13. Police GOK (2005) Police and Criminal evidence for serious crime, give finger prints to Criminal Investigating Department.

14. Smith MED, Kaye H (2001) DNA Data from Everyone Would Combat Crime.

15. Crime Retention, Destruction and use of the finger prints and samples Police Act' 2010.

16. CBS (2010) Population and Housing census for 2009, Ministry of Finance and planning Nairobi Kenya.

17. Strub FG, Clearance G (1989) The principles and practice of embalming 5th edition.

18. Kuhne F (1916) The Origin, Classification and Uses of Finger Prints, An Ideal System of Identification for the General Public. Sci Am 114: 357-366.

19. Olumbe C (2002) Hand book of text book of forensic medicine and medical legal in Kenya.

20. Chen L, Evans T (2004) Human resources for health: overcoming the crisis. Lancet 364: 1984-90.

21. GOK (2005) Police and criminal evidence for serious crime given finger prints to Criminal Investigation Department of forensic identification Government of Kenya, Police Service.

22. Anyumba G, (1990) Kisumu town History of built form, Planning and environment. Netherlands $61-70$

23. GOK (2014) Government of Kenya: Population of local authorities with Towns, County's Administrative and Political Units.

24. Calverton M (2009) Demographic Health and Survey, CBS and ORC Macro Ministry for Public health and sanitation. Nairobi Kenya 114-119

25. KSPA (2010) Traditional and cultural belies in Kenyan community. Kenya Service Provision assessment.

26. GRSP (2012) Global road Safety Partnership.

27. Shilaro PM (2000) Luhya land right and Kakamega Gold rush 1930-1952. PhD (history) university of West Virginia pg 154-6 and 180-186.

28. Interpol (2014) Guidelines concerning Transmission of finger prints crime scene marks.

29. Haines A, Kuruvilla S, Borchert M (2004) Bridging the implementation gap between knowledge and action for health. WHO 82: 724-31.

30. Robert M (2003) Embalming history, theory and practice 3rd edition

31. WHO (1997) Health challenges are influenced by bad health practices which forms major difficulty in achieving quality healthcare in developing countries.

32. WHO (2007) Report attributed to Kenya Traffic Police.

33. Swanton B, Wilson P, Hill L (2008) Missing persons Australian institute of Criminology Canberra. 